\title{
El acceso a la Corte Interamericana de Derechos Humanos y la realización de los derechos a la verdad, la justicia y la reparación en Colombia *
}

\section{The Access to the Inter-American Court of Human Rights and the Implementation of the Rights to Truth, Justice and Reparation in Colombia}

\author{
Corina Duque Ayala **
}

Fecha de recepción: 14 de abril de 2008

Fecha de aprobación: 21 de abril de 2008

\section{Resumen}

Este artículo pretende explicar el origen de la Corte Interamericana de Derechos Humanos (CIDH), su contribución en la garantía de los Derechos Humanos, el procedimiento para acceder a ella, y los logros alcanzados con algunos de sus fallos en nuestro Estado, con respecto a la búsqueda de la verdad judicial, justicia y reparación integral a las víctimas; el derecho de toda víctima de acceder al recurso judicial efectivo

\section{Palabras clave}

Derecho a la verdad judicial, reparación integral y Derechos Humanos.

* Producción colectiva del Grupo de Investigación de la Especialización Derecho Administrativo. Línea: Acceso a las Cortes Internacionales.

** Coautoría de estudiantes: César Tibamoso Flechas, Óscar Villamizar, Henry Rodríguez Ramón Sánchez, Paola Barrera, Camilo Hurtado, Bernardo Bermúdez, Vladimir Castro, Jorge Lara, Sandra Faura y Alexandra Vásquez Veloza., bajo la coordinación de la profesora, Corina Duque Ayala, docente de la facultad de Derecho de la Universidad Santo Tomás. 


\section{Abstract}

This rehearsal looks for to leave certain the origin of the $\mathrm{CIDH}$, its contribution in the guarantee of the human rights, the procedure to consent to her, and the achievements reached with some of its shortcomings in our state, regarding the search of the judicial truth, justice and integral repair to the victims; the right of everything kills of consenting to the effective judicial resource.

\section{Key words}

Right to the judicial truth, integral repair and human rights.

\section{INTRODUCCIÓN}

El presente artículo permite conocer, de forma general, el procedimiento para acceder a la $\mathrm{CIDH}$, y las garantías que ésta ofrece con respecto a la violación de los derechos, libertad personal, integridad personal, la vida, garantías judiciales y la protección judicial, tanto de las víctimas como de sus familiares, consagrados en la Convención Americana sobre Derechos Humanos.

Asimismo, el estudio del tema abordado es de vital importancia, debido al impacto social y jurídico que produce, tanto a nivel nacional como internacional. Se va a exponer la situación relacionada con el acceso a la justicia internacional -concretamente a la Corte Interamericana de Derechos Humanosde casos relacionados con el conflicto interno colombiano, en el ámbito internacional, acontecer que se encuentra íntimamente ligado al tema de la impunidad, temas que se han desarrollado o vivido en contextos específicos, toda vez, que se han sometido conflictos puntuales a su resolución, en busca de una responsabilidad Estatal.

Del tema contenido se puede inferir que el Estado colombiano debe activar y completar la investigación de las masacres, a fin de juzgar y sancionar a todos los autores materiales e intelectuales. Las sentencias de la Corte Interamericana constituyen un aporte significativo en la búsqueda de justicia, verdad y reparación de los sobrevivientes y familiares de las víctimas de las masacres perpetuadas en Colombia.
Como es sabido, el acceso a esta jurisdicción es bastante limitado, tanto por las condiciones para procesar la acción, como por los recursos económicos requeridos para su acceso. En otras palabras, el hecho de que un Estado no esté estimulado a considerar esos efectos reflejos propios de las sentencias de la Corte Interamericana, constituye per se una violación a sus obligaciones internacionales, en cuanto le imponen el compromiso, cada vez en mayor medida, de la defensa y garantía de los Derechos Humanos de todas las personas bajo su jurisdicción.

Con respecto a los antecedentes históricos, la Corte Interamericana de Derechos Humanos fue creada en 1969 por la Convención Americana sobre Derechos Humanos; a partir de 1979 se reunió por primera vez la Corte y desde ese momentos se ha posicionado como la institución judicial del sistema interamericano que, junto con la Comisión Interamericana de Derechos Humanos, han sido fundamentales en la promoción, respeto y garantía de los Derechos Humanos en el continente americano.

En noviembre de 1969 se celebró en San José de Costa Rica la Conferencia Especializada Interamericana sobre Derechos Humanos. En ella, los delegados de los Estados miembros de la Organización de los Estados Americanos redactaron la Convención Americana sobre Derechos Humanos, que entró en vigor el 18 de julio de 1978, al haber sido depositado el undécimo instrumento de ratificación por un Estado miembro de la OEA. 
Veinticinco naciones americanas han ratificado o se han adherido a la Convención: Argentina, Barbados, Bolivia, Brasil, Colombia, Costa Rica, Chile, Dominica, Ecuador, El Salvador, Grenada, Guatemala, Haití, Honduras, Jamaica, México, Nicaragua, Panamá, Paraguay, Perú, República Dominicana, Suriname, Trinidad y Tobago, Uruguay y Venezuela. Trinidad y Tobago denunció la Convención Americana sobre Derechos Humanos por comunicación dirigida al Secretario General de la OEA, el 26 de mayo de 1998.

Este tratado regional es obligatorio para aquellos Estados que lo han ratificado o se haya adherido a él y representa la culminación de un proceso que se inició a finales de la Segunda Guerra Mundial, cuando las naciones de América se reunieron en México y decidieron que una declaración sobre Derechos Humanos debía ser redactada, para que pudiera ser eventualmente adoptada como convención. Tal declaración, la Declaración Americana de los Derechos y Deberes del Hombre fue aprobada por los Estados miembros de la OEA en Bogotá, en mayo de 1948.

Con el objeto de salvaguardar los derechos esenciales del hombre en el continente americano, la Convención instrumentó dos órganos competentes para conocer de las violaciones a los Derechos Humanos: la Comisión Interamericana de Derechos Humanos y la Corte Interamericana de Derechos Humanos. La primera fue creada en 1959 e inició sus funciones en 1960, cuando el Consejo de la OEA aprobó su Estatuto y eligió sus primeros miembros.

El Tribunal no se pudo establecer y organizar hasta que entró en vigor la Convención. El 22 de mayo de 1979 los Estados partes en la Convención Americana eligieron, durante el séptimo periodo extraordinario de sesiones de la Asamblea General de la OEA, a los juristas, que en su capacidad personal, serían los primeros jueces que compondrían la Corte Interamericana. La primera reunión de la Corte se celebró el 29 y 30 de junio de 1979 en la sede de la OEA en Washington D.C. La Asamblea General de la OEA, el 1 de julio de 1978, recomendó aprobar el ofrecimiento formal del gobierno de Costa Rica para que la sede de la Corte se estableciera en ese país. Esta decisión fue ratificada después por los Estados partes en la Convención, durante el sexto periodo extraordinario de sesiones de la Asamblea General, celebrado en noviembre de 1978. La ceremonia de instalación de la Corte se realizó en San José el 3 de septiembre de 1979.

El 10 de septiembre de 1981 el gobierno de Costa Rica y la Corte firmaron un Convenio de Sede, aprobado mediante Ley No. 6889 del 9 de septiembre de 1983, que incluye el régimen de inmunidades y privilegios de la Corte, de los jueces, del personal y de las personas que comparezcan ante ella. Este Convenio de Sede está destinado a facilitar el desenvolvimiento normal de las actividades de la Corte, especialmente, por la protección que da a todas aquellas personas que intervengan en los procesos. Como parte del compromiso contraído por el gobierno de Costa Rica, en noviembre de 1993, éste le donó a la Corte la casa que ocupa la sede del Tribunal, actualmente.

Sus primeros fallos se caracterizaron por el constante dinamismo jurídico de su jurisprudencia, lo cual redunda en la protección cada vez más amplia de los Derechos Humanos. En consecuencia, y en virtud de los cambios en años recientes de los Reglamentos de la Comisión y de la Corte, se están presentando casos para su resolución y solicitudes de consultas. Es importante conocer el procedimiento ante los órganos del sistema interamericano en todas sus fases, por lo que es preciso estudiar cada uno de sus fallos, tomando como referente las posiciones presentadas por las partes, para así poder comprender la interrelación que debe existir entre las posiciones de las partes que integran la litis y el fallo emitido por la Corte. Aunado a lo 
anterior, la interrelación e interdependencia de las diferentes ramas del Derecho Internacional -sea de carácter universal o regional- debe ser más estrecha, por lo que es necesario observar cómo la Corte incorpora las distintas fuentes del Derecho Internacional en su actuar.

Para efectos de trámite de los casos por violaciones a los Derechos Humanos, por parte de un Estado miembro, las directamente competentes son la Comisión y la Corte Interamericana que desarrollan una función de protección y coerción "protectiva y sancionadora". Por lo anterior y en virtud de que esta labor de análisis está representando un reto para los académicos que dan seguimiento al trabajo de la Corte, por los variados y específicos temas que se abordan dentro de la línea jurisprudencial de sus resoluciones.

\section{ASPECTOS RELEVANTES DE LA COMISIÓN INTERAMERICANA DE DERECHOS HUMANOS}

La Comisión Interamericana de Derechos Humanos (CIDH) fue creada en 1959, en una reunión extraordinaria de la OEA; es el órgano en el cual un particular puede presentar su caso -vía Internet si lo desea. Está compuesta por siete miembros, que son elegidos por la Asamblea General de la OEA, por propuesta de los Estados y deben ser nacionales de cualquier Estado miembro de la Organización.

Sus funciones son tramitar las quejas referentes a violaciones de Derechos Humanos, que constituyan una violación sistemática en la esfera internacional; todos los Estados miembros de la OEA están sometidos a sus estatutos y su reglamentación sin necesitad de ratificación de un tratado. Sin embargo, el trámite interno varía un poco y depende de si el Estado ratificó o no el Pacto de San José de Costa Rica. Si no lo ratificó la base legal para el Estado es la legislación general contenida en la
Declaración Americana de los Derechos y Deberes del Hombre.

De igual forma, la Corte Interamericana de Derechos Humanos tiene dos funciones específicas, una jurisdiccional, mediante la cual se estudia la responsabilidad de los Estados, pero teniendo presente el acontecer fáctico planteado como trasgresión a la Convención Americana de Derechos Humanos. A su vez, tiene la función consultiva, atribuciones que se desprenden de la competencia de la misma característica, ya que cualquier Estado miembro puede indagar a la Corte con respecto a la interpretación o aplicación de la Convención, al igual que de los tratados atinentes a la protección de los Derechos Humanos.

\section{REQUISITOS DE LAS PETICIONES DIRIGIDAS A LA CIDH}

- Nombre, nacionalidad y firma de la persona o personas denunciantes o, en el caso de que el peticionario sea una entidad no gubernamental, el nombre y la firma de su representante o representantes legales.

- Si el peticionario desea que su identidad sea mantenida en reserva frente al Estado, debe solicitarlo expresamente.

- Dirección para recibir correspondencia de la Comisión, indicando número de teléfono, fax y dirección de correo electrónico.

- Relación del hecho "aspectos fácticos" o situación denunciada, con especificación del lugar $y$ fecha de las violaciones alegadas.

- De ser posible, el nombre de la víctima, así como de cualquier autoridad pública que haya tomado conocimiento del hecho o situación denunciada.

- Indicación del Estado que el peticionario considera responsable, por acción o por omisión, de la violación de alguno de los Derechos Huma- 
nos consagrados en la Convención Americana sobre Derechos Humanos y otros instrumentos aplicables, aunque no se haga una referencia específica al artículo presuntamente violado.

- Cumplimiento con el plazo previsto en el artículo 32 del presente Reglamento: $1^{\circ}$ de enero de 1980.

- Indicación de las gestiones emprendidas para agotar los recursos de la jurisdicción interna o la imposibilidad de hacerlo conforme al artículo 31 del presente reglamento.

- Indicación de si la denuncia ha sido sometida a otro procedimiento de arreglo internacional conforme al artículo 33 del presente Reglamento.

Según instrucciones de la Comisión en su página Web: el formulario debe ser llenado de la manera más completa posible e incluir toda la información disponible, en relación con uno o más hechos en particular que constituya una o más violaciones a Ios Derechos Humanos por parte de Estados miembros de la OEA. La redacción de las respuestas debe ser sencilla y directa. Una vez completo, el formulario debe ser enviado oprimiendo el botón "enviar formulario", si usted no tiene acceso a Internet, el formulario se encuentra también en formato PDF, que puede ser impreso y enviado por el correo a la siguiente dirección postal:

Comisión Interamericana de Derechos Humanos 1889 F Street, N. W. Washington, D.C. 2006, USA

Por Fax al siguiente número:1-202- 458-3992. Vía Internet a la dirección de la Comisión.

La Corte Interamericana de Derechos Humanos es una institución judicial autónoma cuyo objetivo es la aplicación e interpretación de la Convención Americana sobre Derechos Humanos, la cual ejerce sus funciones de conformidad con las disposiciones de la citada Convención y del Estatuto (Estatuto de la Corte Interamericana de Derechos Humanos, s.f.).
La Comisión Interamericana de Derechos Humanos (CIDH) es una de las dos entidades del sistema interamericano de protección y promoción de los Derechos Humanos en la América. Tiene su sede en Washington, D.C. El otro órgano es la Corte Interamericana de Derechos Humanos con sede en San José, Costa Rica. Estas entidades tienen la función principal de promover la observancia y la defensa de los Derechos Humanos, por lo tanto, gozan de sus propias reglas, diferentes a las del derecho interno, y busca determinar la responsabilidad estatal y no la responsabilidad penal de individuos.

En consecuencia, la Corte Interamericana es el máximo tribunal internacional de Derechos Humanos de América; sus facultades se emanan de la Convención Americana sobre Derechos Humanos, la cual es ley en veinticinco países, incluido Colombia, los cuales se comprometieron a cumplir los fallos expedidos por la Corte en todo caso. Para ello, los Estados deben asegurar la implementación a nivel interno de lo dispuesto por el Tribunal en sus decisiones ${ }^{1}$.

Dichas disposiciones tienen un carácter definitivo e inapelable, según lo establecido en el artículo 67 de la Convención, éstas deben ser prontamente acatadas por el Estado en forma íntegra. Lo anterior, según lo dispuesto en las sentencias del Tribunal corresponde a un principio básico del derecho de la responsabilidad internacional del Estado, respaldado por la jurisprudencia de las cortes internacionales, según la cual los Estados deben obedecer sus obligaciones convencionales internacionales de buena fe (pacta sunt servanda) y

$1 \quad$ Al respecto consultar: Caso Comunidad indígena Sawhoyamaxa. Cumplimiento de Sentencia. Resolución de la Corte Interamericana de Derechos Humanos del 2 de febrero de 2007, Considerando segundo; Caso Yatama. Cumplimiento de Sentencia. Resolución de la Corte Interamericana de Derechos Humanos del 29 de noviembre de 2006, Considerando tercero, y Caso Cesti Hurtado. Cumplimiento de Sentencia. Resolución de la Corte Interamericana de Derechos Humanos de 22 de septiembre de 2006. 
aquéllos no pueden, por razones de orden interno, dejar de asumir la responsabilidad internacional ya establecida ${ }^{2}$. Las obligaciones convencionales de los Estados partes vinculan a todos los poderes y órganos del Estado.

Según un principio básico del Derecho Internacional de los Derechos Humanos, el Estado tiene la obligación de investigar las violaciones de Derechos Humanos, sancionar a los responsables y reparar a las víctimas y a sus familiares. Al suscribir tratados internacionales como el Pacto Internacional de Derechos Civiles y Políticos y la Convención Americana sobre Derechos Humanos, el Estado colombiano ha asumido ante la comunidad internacional dos obligaciones básicas: la de respetar y la de garantizar los derechos enunciados en cada uno de esos instrumentos. Así se infiere de lo estipulado en el artículo $2^{\circ}$ del Pacto y en el artículo $1^{\circ}$ de la Convención.

El Pacto Internacional de Derechos Civiles y Políticos y la Convención Americana sobre Derechos Humanos son instrumentos convencionales que pertenecen a una rama específica del Derecho Internacional Público: el Derecho Internacional de los Derechos Humanos, cuyo objeto y fin es "la protección de los derechos fundamentales de los seres humanos, independientemente de su nacionalidad, tanto frente a su propio Estado como frente a los otros Estados contratantes" (Corte Interamericana de Derechos Humanos, 24 de diciembre de 1982, §. 29). Del Derecho Internacional de los Derechos Humanos hacen parte normas consuetudinarias y convencionales adoptadas para apoyar, ayudar y complementar la guarda que sobre esos derechos establece la normativa interna de cada país.

2 Consultar: Caso Comunidad Indígena Sawhoyamaxa. Cumplimiento de Sentencia, nota 1, Considerando tercero; Caso Yatama. Cumplimiento de Sentencia, Considerando quinto y Caso Cesti Hurtado. Cumplimiento de Sentencia, Considerando séptimo.

\section{LAS VIOLACIONES DE LOS DERECHOS HUMANOS Y LOS CRÍMENES DE LESA HUMANIDAD}

Algunos emplean como expresiones equivalentes la violación de los derechos humanos y la de crimen de lesa humanidad. Es bueno dejar en claro que con esas expresiones se identifican categorías jurídicas hoy en día pertenecientes a dos ordenamientos internacionales distintos. La violación de los Derechos Humanos es una figura propia del Derecho Internacional de los Derechos Humanos, mientras que el crimen de lesa humanidad es una figura propia del Derecho Penal Internacional. Por lo demás, las violaciones de los Derechos Humanos se pueden dar sin necesariamente cometer dichos crímenes.

En el Derecho Penal Internacional se denominan crímenes de lesa humanidad ciertas conductas violentas, enunciadas por el artículo $7^{\circ}$ del Estatuto de la Corte Penal Internacional, cuando se cometen "como parte de un ataque generalizado o sistemático contra una población civil y con conocimiento de dicho ataque". Entre los crímenes de lesa humanidad figuran el asesinato, el exterminio, la esclavitud, la deportación o traslado forzoso de población, la encarcelación u otra privación grave de la libertad física en violación de normas fundamentales de Derecho Internacional, la tortura, la violación, la persecución, la desaparición forzada de personas y el apartheid.

En Colombia, los graves abusos contra los Derechos Humanos se mantienen en las zonas rurales, pese a la constante reducción de ciertos tipos de violencia asociada al prolongado conflicto armado interno, en particular, los secuestros y los homicidios. Todas las partes implicadas en el conflicto, como las fuerzas de seguridad y los paramilitares respaldados por el Ejército, así como los grupos guerrilleros, sobre todo, las Fuerzas Armadas Revolucionarias de Colombia (FARC) y el Ejército de 
Liberación Nacional (ELN), continúan cometiendo abusos contra los Derechos Humanos y vulnerando el Derecho Internacional Humanitario. Siendo responsables de crímenes de guerra y de lesa humanidad con ejecuciones extrajudiciales.

De igual forma, es de público conocimiento la manifestación sobre la responsabilidad internacional de Colombia por haber emitido un marco legal a través del cual se propició la creación de grupos de autodefensa, que derivaron posteriormente en paramilitares y por la falta de adopción de todas las medidas necesarias para, de forma efectiva, terminar con la situación de riesgo creada por el propio Estado a través de dichas normas. Por ejemplo:

[...] En los casos en los cuales paramilitares y miembros del Ejército llevan a cabo operaciones conjuntas o cuando los paramilitares actúan gracias a la aquiescencia o colaboración de la Fuerza Pública, debe considerarse que los miembros de los grupos paramilitares actúan como agentes estatales.

El Estado permitió la colaboración y la participación de particulares en la realización de ciertas funciones, como patrullaje militar en zonas de orden público, utilizando armas de uso privativo de las Fuerzas Armadas o en desarrollo de actividades de inteligencia militar, que por lo general son de competencia exclusiva del Estado y en las cuales éste adquiere una especial función de garante. En consecuencia, el Estado es directamente responsable, tanto por acción como por omisión, de todo lo que hagan estos particulares en ejercicio de dichas funciones, más aún, si se tiene en cuenta que los particulares no están sometidos al escrutinio estricto que pesa sobre un funcionario público con respecto al ejercicio de sus funciones.

Este principio general queda confirmado en muchos contextos distintos, como por ejemplo, es responsable si no cumplen con las obligaciones que han contraído en virtud de los tratados, incluidos los de Derechos Humanos y del Derecho Consuetudinario Internacional, poniendo en relieve las responsabilidades jurídicas internacionales de los Estados con respecto a las acciones de los agentes no estatales.

En este sentido, los Estados tienen el compromiso jurídico de respetar y aplicar el Derecho Internacional de Derechos Humanos en su territorio y en los territorios donde tengan control efectivo y jurisdicción; no sólo deben respetar los derechos, absteniéndose de violar Derechos Humanos ellos mismos por medio de sus agentes y su aparato institucional, sino también a proteger los derechos frente a abusos cometidos por otros y a promover el cumplimiento de los Derechos Humanos en un sentido más amplio.

Entonces, la responsabilidad internacional del Estado se funda en "actos u omisiones de cualquier poder u órgano de éste, independientemente de su jerarquía, que violen la Convención Americana" ${ }^{\prime 3}$. Para establecer que se ha producido una violación de los derechos consagrados en la Convención no se requiere determinar, como ocurre en el Derecho Penal interno, la culpabilidad de sus autores o su intencionalidad y tampoco es preciso identificar individualmente a los agentes a los que se atribuyen los hechos violatorios ${ }^{4}$. Es suficiente la demostración de que ha habido apoyo o tolerancia del poder público en la infracción de los derechos reconocidos en la Convención ${ }^{5}$, omisiones que hayan permitido la perpetración de

3 Consultar: Caso del Penal Miguel Castro Castro, § 31; Caso Masacre de Pueblo Bello, § 112; y Caso de la Masacre de Mapiripán, § 110.

4 Consultar: Caso La Cantuta, § 156; Caso Masacre de Pueblo Bello, nota 12, § 112; y Caso de la Masacre de Mapiripán, nota 12, § 110.

5 Consultar: Caso 19 Comerciantes. Sentencia de 5 de julio de 2004. Serie C No. 109, § 141. En igual sentido, consultar Caso Cantos. Sentencia de 28 de noviembre de 2002. Serie C No. 97 , $\S 28 ;$ y Caso Hilaire, Constantine y Benjamin y otros. Sentencia de 21 de junio de 2002. Serie C No. 94, § 66 . 
esas violaciones o que exista una obligación del Estado que haya sido incumplida por éste ${ }^{6}$.

Los Estados partes en la Convención tienen obligaciones erga omnes de respetar y hacer respetar las normas de protección y de asegurar la efectividad de los derechos allí consagrados en toda circunstancia y respecto de toda persona. La atribución de responsabilidad al Estado por actos de particulares se puede dar en casos en que el Estado incumple, por acción u omisión de sus agentes cuando se encuentren en posición de garantes, esas obligaciones erga omnes contenidas en los artículos 1.1 y 2 de la Convención.

\section{COMPETENCIAS DE LA CIDH}

\section{Contenciosa}

La Corte tiene competencia para conocer de cualquier caso relativo a la interpretación y aplicación de las disposiciones de la Convención Americana sobre Derechos Humanos que le sea sometido, siempre que los Estados partes en el caso, hayan reconocido o reconozcan dicha competencia, por declaración especial o por convención especial. Básicamente, conoce los casos en que se alegue que uno de los Estados partes ha violado un derecho o libertad protegidos por la Convención, siendo necesario que se hayan agotado los procedimientos previstos en ésta.

La Comisión puede llevar un asunto ante la Corte, siempre que el Estado cuestionado haya aceptado su competencia. De todas maneras, la Comisión debe comparecer en todos los casos ante la Corte. El procedimiento ante la Corte es de carácter contradictorio; termina con una sentencia motivada, obligatoria, definitiva e inapelable. Si el fallo no expresa en todo o en parte la opinión unánime

6 Consultar: Caso Masacre de Pueblo Bello, nota 12, § 112; Caso de la Masacre de Mapiripán, nota 12, §110; y Caso 19 Comerciantes, nota $33, \S 141$. de los jueces, cualquiera de éstos tiene derecho a que se agregue al fallo su opinión disidente o individual. En caso de desacuerdo sobre el sentido o alcance del fallo, la Corte lo interpreta a solicitud de cualquiera de las partes, siempre que dicha solicitud se presente dentro de los noventa días a partir de la fecha de la notificación del fallo.

\section{Consultiva}

Los Estados miembros de la OEA pueden consultar a la Corte sobre la interpretación de la Corte Interamericana de Derechos Humanos o de otros tratados concernientes a la protección de los Derechos Humanos en los Estados americanos. Además, pueden consultarla en los que les compete, los órganos de la Organización de los Estados Americanos. Asimismo, la Corte, por solicitud de un Estado miembro de la OEA, puede darle a tal Estado opiniones acerca de la compatibilidad entre cualquiera de sus leyes internas y los mencionados instrumentos internacionales (Niklen, s.f.).

La Corte no puede obviar la existencia de deberes generales y especiales de protección de la población civil a cargo del Estado, derivados del Derecho Internacional Humanitario, en particular del artículo 3 común de los Convenios de Ginebra del 12 de agosto de 1949 y las normas del Protocolo adicional a los Convenios de Ginebra relativo a la protección de las víctimas de los conflictos armados de carácter no internacional (Protocolo II). El respeto debido a las personas protegidas implica obligaciones de carácter pasivo (no matar, no violar la integridad física), mientras que la protección debida implica obligaciones positivas de impedir que terceros perpetren violaciones contra dichas personas.

Las obligaciones derivadas de dicha normativa internacional deben ser tomadas en cuenta, según lo dispuesto en el artículo 29.b) de la Convención, pues quienes se hallan protegidos por el régimen de dicho instrumento no pierden por ello los derechos o facultades que ya tengan conforme a la legislación 
del Estado bajo cuya jurisdicción se encuentran, sino que, se complementan o integran para precisar su alcance o determinar su contenido.

En un análisis especial, la Corte estima que la inefectividad de los procesos penales internos en Colombia queda claramente evidenciada al analizar la falta de la debida diligencia en la conducción de las acciones oficiales de investigación, falta que se manifiesta en la irrazonabilidad del plazo transcurrido en las investigaciones, la falta de adopción de las medidas necesarias de protección ante las amenazas que se presentaron durante las investigaciones, las demoras, obstáculos y obstrucciones en la realización de actuaciones procesales y graves omisiones en el seguimiento de líneas lógicas de investigación.

El eje central del análisis de la efectividad de los procesos judiciales es el cumplimiento de la obligación de investigar con debida diligencia, es decir, que el órgano que investiga una violación de Derechos Humanos debe utilizar todos los medios disponibles para llevar a cabo, dentro de un plazo razonable, todas aquellas actuaciones y averiguaciones que sean necesarias, a fin de intentar obtener el resultado que se persigue ${ }^{7}$. Este procedimiento adquiere particular importancia ante la gravedad de los delitos cometidos y la naturaleza de los derechos lesionados que se pretendan investigar.

Al respecto, la Corte recuerda su jurisprudencia constante sobre la inadmisibilidad de las disposiciones de amnistía, las disposiciones de prescripción y el establecimiento de excluyentes de responsabilidad, que pretendan impedir la investigación y, en su caso, la sanción de los responsables de las violaciones graves de los Derechos Humanos como la tortura, las ejecuciones sumarias, extralegales o arbitrarias y las desapariciones forzadas, todas ellas

7 Confrontar: Caso Gómez Palomino, nota 119, § 80; y Caso de las Hermanas Serrano Cruz. Sentencia de 1 de marzo de 2005. Serie C No. 120, § 83. prohibidas por contravenir derechos inderogables reconocidos por el Derecho Internacional de los Derechos Humanos.

El Estado está obligado a combatir esta situación de impunidad por todos los medios disponibles, ya que ésta propicia la repetición crónica de las violaciones de Derechos Humanos y la total indefensión de las víctimas y de sus familiares, los cuales tienen derecho a conocer la verdad de los hechos. El reconocimiento y el ejercicio del derecho a la verdad en una situación concreta constituyen un medio de reparación.

Según la Corte, el Estado debe "remover todos los obstáculos, de facto y de jure, que mantengan la impunidad", lo que es interpretado por algunos como no beneficiar con legislación especial a personas halladas responsables de crímenes de lesa humanidad. Por ejemplo, para el caso colombiano una prueba de impunidad puede ser la del señor Salvatore Mancuso, quien fue condenado por un tribunal de Antioquia, en abril de 2003, a cuarenta años de cárcel por la masacre de El Aro, y si se le aplica los beneficios de la ley de "Justicia y Paz" sólo pagará como condena máximo ocho años de cárcel. La pregunta es si la Corte Interamericana considera que el proceso adelantado en este caso cumple las garantías y los requisitos establecidos en el Estatuto Interamericano de Derechos Humanos, para juzgar los crímenes de lesa humanidad.

Por lo tanto, la reparación del daño ocasionado por la infracción de una obligación internacional requiere, siempre que sea posible, la plena restitución restitutio in integrum, la cual consiste en el restablecimiento de la situación anterior a la violación. De no ser esto posible, cabe al tribunal internacional determinar una serie de medidas, para que, además de garantizar el respeto de los derechos conculcados, se reparen las consecuencias producidas por las infracciones y se establezca 
inter alia el pago de una indemnización, como compensación por los daños ocasionados. La obligación de reparar, que se regula en todos los aspectos -alcance, naturaleza, modalidades y determinación de los beneficiarios- por el Derecho Internacional no puede ser modificada o incumplida por el Estado obligado invocando disposiciones de su derecho interno.

Las reparaciones consisten en las medidas que tienden a hacer desaparecer los efectos de las violaciones cometidas. Su naturaleza y su monto dependen del daño ocasionado en los planos material e inmaterial. Las reparaciones no pueden implicar ni enriquecimiento, ni empobrecimiento para la víctima o sus sucesores.

A continuación se sintetizan algunos de los casos de violaciones al Derecho Internacional Humanitario en Colombia, que han sido estudiados por la Corte Interamericana de Derechos Humanos.

\section{LOS DIECINUEVE COMERCIANTES}

"El contrabando se castigó con la desaparición". En octubre de 1987 diecinueve personas, la mayoría de ellas dedicadas al comercio de mercancía de contrabando, fueron torturadas y desaparecidas por miembros del Batallón Bárbula y paramilitares del grupo al mando de Henry de Jesús Pérez Duran, por orden del brigadier general Farouk Yanine Díaz, quien para el momento de los hechos se desempeñaba como Director de la Escuela Militar de Cadetes. El crimen fue justificado con la falsa acusación de que los comerciantes transportaban armas para la guerrilla, pero según familiares de las víctimas:

[...] éstos se movilizaban por una zona donde la guerrilla tenía presencia y cuando pasaban por los retenes debían pagar una cuota con contrabando, por ejemplo, les pedían que les trajeran crema dental y cosas de aseo personal; ellos nunca tuvieron problemas con la guerrilla porque siempre les pagaban la cuota que pedían, pero esa era la única relación que tenían con la guerrilla, por eso ya los paramilitares como que los habían amenazado.

El 8 de octubre de 1987, diecisiete de las víctimas se movilizaban en caravana de cuatro vehículos (un camión, un campero, una camioneta y un taxi) a Medellín (Antioquia), con mercancía de contrabando que traían de Venezuela, avaluada en 70 millones de pesos, cuando fueron interceptados en la Inspección de Policía Puerto Araujo, de Cimitarra, por los miembros del Batallón $\mathrm{Ca}$ libío: teniente Néstor Raúl Vargas Morales y los cabos segundos José Emilio Meléndez Portilla y Luis Eduardo Vera Nieto, quienes los retuvieron durante un tiempo, mientras, al parecer, avisaban por radioteléfono a los paramilitares; luego los dejaron ir; desde allí algunas de las víctimas Ilamaron a sus familias, lo que fue la última vez que supieron de ellos.

Cuando las víctimas llegaron al sitio Lizama los paramilitares los estaban esperando. Según declaraciones de miembros del grupo, a los comerciantes los detuvieron, los torturaron y los descuartizaron, lanzando luego sus cuerpos al río Ermitaño, en un sitio llamado El Mango, en jurisdicción de la inspección de policía Zambito. Los cuerpos nunca fueron encontrados. Con la mercancía que les quitaron montaron un almacén en la plaza principal, en el piso inferior de los juzgados de Puerto Boyacá, manejado por la esposa de un jefe paramilitar; el cual, a raíz de las investigaciones, fue cerrado y la mercancía repartida entre los miembros de la Asociación de Campesinos y Ganaderos del Magdalena Medio (ACDEGAM). Los carros que les quitaron fueron escondidos bajo unas carpas prestadas por el alcalde de Puerto Boyacá, Luis Alfredo Rubio Rojas, pero cuando se percataron de que el caso estaba siendo investigado, decidieron desaparecer también los automotores, por lo que los cortaron con soplete y los lanzaron a un lago ubicado en la hacienda El Diamante. 
El 18 de octubre, al no saber nada del paradero de las diecisiete personas y luego de recibir una llamada anónima en la que decían "vayan por los cuerpos que están siendo pasto de las aves de rapiña", la esposa de Víctor Manuel Ayala Sánchez y Juan Alberto Montero, un hermano de ella, decidieron desplazarse a la zona a buscarlos. Llegaron hasta La Dorada (Caldas) y allí buscaron a José Ferney Fernández Díaz, un amigo de Juan Alberto. Juan Alberto y José Ferney se dirigieron a Puerto Boyacá en una motocicleta de propiedad de éste último, corriendo con la misma suerte; cuando se movilizaban por la vía a Puerto Boyacá, fueron vistos por los paramilitares conocidos con los alias Pedro Mugre y Mata Patos, quienes avisaron a la hacienda El Diamante de la presencia de dos personas que estaban indagando por los diecisiete desaparecidos. Más adelante fueron obligados a bajar de la motocicleta en un retén y fueron asesinados a machete, los cuerpos fueron arrojados en unos costales y tirados al río Ermitaño.

La esposa de Víctor Manuel Ayala llegó hasta el municipio de Puerto Boyacá en busca de su esposo y su hermano, allí un señor de una tienda le dijo que era mejor que se devolviera para La Dorada si no quería que le sucediera lo mismo que a ellos, asimismo, el inspector de policía le dijo que desde que había llegado al pueblo la estaban siguiendo; por lo que se vio presionada a abandonar Puerto Boyacá.

\section{LA MASACRE DE LA ROCHELA}

En el presente caso, el Estado confesó que el 18 de enero de 1989, por lo menos cuarenta miembros del grupo paramilitar Los Masetos, contaron con la cooperación y aquiescencia de agentes estatales. Inicialmente, retuvieron a las quince víctimas de este caso, quienes conformaban una Comisión Judicial (Unidad Móvil de Investigación) compuesta por dos jueces de Instrucción Criminal, dos secretarios de juzgado y once miembros del Cuerpo Técnico de la Policía Judicial (CTPJ) y posteriormente perpetró una masacre en su contra, en la cual fueron ejecutados doce de ellos y sobrevivieron tres.

Resulta de gran relevancia destacar que uno de los principales factores que determinaron la gravedad de los hechos en este caso es que el Estado es responsable de una masacre perpetrada contra sus propios funcionarios judiciales, cuando se encontraban cumpliendo con su deber de investigar graves violaciones de Derechos Humanos y que en dicha masacre, inclusive, participaron agentes estatales pertenecientes a las Fuerzas Armadas.

Los hechos del presente caso se constituyen en un conjunto de violaciones contra funcionarios judiciales y estaban dirigidas a impedir sus labores, intimidarlos, amedrentarlos y así lograr la impunidad de graves violaciones a los Derechos Humanos. Fue en ese contexto de riesgo para los funcionarios judiciales que el Estado no adoptó las medidas necesarias para garantizar la seguridad de los miembros de la Comisión Judicial en el cumplimiento de sus labores, situación reconocida en varias sentencias del Consejo de Estado $^{8}$ y omisión reconocida por Colombia en el proceso internacional.

La Corte consideró que en el presente caso es atribuible la responsabilidad internacional al Estado con fundamento en que:

- El Estado estableció un marco legal a través del cual se propició la creación de grupos de autodefensa, que contaban con el apoyo de las autoridades estatales y que derivaron en para-

8 Confrontar las sentencias emitidas los días 19 de mayo de 1995, 1 de febrero de 1996, 5 de julio de 1996 y 29 de agosto de 1996 por el Consejo de Estado, Sala de lo Contencioso Administrativo, Sección Tercera (expediente de anexos al escrito de contestación de la demanda presentados por el Estado, Tomo II, folios 5313 a 5327, 5190 a 5204, 5257 a 5291, 5346 a 5291). 
militares. El Estado les otorgaba permisos para el porte y tenencia de armas de uso privativo de las Fuerzas Armadas.

- Las violaciones ocurrieron en una época en que ese marco legal se encontraba vigente, a pesar de que ya habían transcurrido varios años desde que se hizo notoria la transformación de grupos de autodefensa en paramilitares.

- Las violaciones se cometieron en el marco de reglamentos y manuales de combate contra las guerrillas, adoptados por la máxima autoridad de las Fuerzas Militares, que establecían como funciones de los agentes militares organizar "en forma militar" a la población civil en grupos o juntas de autodefensa y ejercer control y autoridad sobre tales grupos, los cuales debían cumplir funciones de patrullaje y apoyo a la ejecución de operaciones de combate y de inteligencia militar.

- El Estado reconoció que los miembros del grupo paramilitar Los Masetos contaron con la cooperación y aquiescencia de agentes estatales para ejecutar la Masacre de La Rochela.

- El Estado reconoció que los miembros de la Comisión Judicial fueron ejecutados mientras estaban investigando crímenes presuntamente cometidos por paramilitares y miembros de la fuerza pública en la zona del Magdalena Medio.

- El objetivo de las violaciones en este caso era ejecutar a los miembros de la Comisión Judicial y sustraer o destruir los expedientes que llevaba dicha comisión en relación con dichas investigaciones.

\section{LA MASACRE DE LAS PALMERAS}

El 23 de enero de 1991, en la localidad de las Palmeras, municipio de Mocoa, departamento de Putumayo, el Comandante Departamental de la Policía de Putumayo ordenó a miembros de la Policía Nacional llevar a cabo una operación armada en el sector de las Palmeras. Ante esta orden la Policía Nacional fue apoyada por efectivos del Ejército.

Se encontraban en la escuela rural de Las Palmeras unos niños; allí laboraban dos trabajadores que reparaban un tanque séptico, quienes se identificaban como Julio Milciades Cerón Gómez y Artemio Pantoja. Igualmente, cerca del sector se hallaban Ios hermanos William Hamilton y Edebraes Norverto, ambos Cerón Rojas, ordeñando una vaca y el maestro Hernán Javier Cuarán Muchavisoy, de repente, las fuerzas del Ejército abrieron fuego desde un helicóptero e hirieron al niño Enio Quinayas Molina, de seis años de edad.

La Policía detuvo en la escuela y en sus alrededores al maestro Cuarán Muchavisoy a los trabajadores Cerón Gómez y Pantoja, a los hermanos William Hamilton y Edebraes Cerón y a otra persona no identificada que podría ser Moisés Ojeda o Hernán Lizcano Jacanamejoy. Se dice que la Policía Nacional ejecutó extrajudicialmente por lo menos a seis de estas personas.

Los miembros de la Policía Nacional y del Ejército para justificar su conducta vistieron con uniformes militares los cadáveres de algunas de las personas ejecutadas, quemaron sus ropas e intimidaron a varios testigos de los hechos. Igualmente, la Policía Nacional reportó siete cadáveres como pertenecientes a grupos subversivos, que habían caído muertos en un presunto enfrentamiento. Supuestamente seis de los cuerpos eran personas detenidas por la Policía y un séptimo, cuyas circunstancias de muerte aún no han sido esclarecidas.

Ante los hechos anteriormente descritos, las autoridades correspondientes iniciaron procesos de carácter disciplinario, administrativo y penal. El proceso disciplinario lo realizó el Comandante de la Policía Nacional de Putumayo, el falló lo profirió a los cinco días siguientes, absolviendo a todos 
Ios efectivos que participaron en los hechos de la localidad de Las Palmeras. De igual forma, se iniciaron dos procesos contencioso-administrativos en los que se reconoció expresamente que las víctimas del operativo armado no pertenecían a ningún grupo armado y que el día de los hechos, estaban realizando sus labores habituales.

Estos procesos permitieron corroborar posteriormente que la Policía Nacional ejecutó extrajudicialmente a las víctimas cuando se encontraban en estado de indefensión. El presente caso fue sometido a la Corte por la Comisión Interamericana el 6 de julio de 1998. La demanda de la Comisión tiene su origen en una denuncia $\left(\mathrm{N}^{\circ} 11.237\right)$ de fecha 27 de enero de 1994 por supuestas violaciones a los Derechos Humanos con respecto a las victimas inicialmente citadas (Corte Interamericana de Derechos Humanos, s.f.).

El 9 de agosto de 1999 la Comisión presentó a la Corte su réplica. En ella le solicitaba que concluyera y declarara que el Estado de Colombia ha violado el derecho a la vida, consagrado en el artículo 4 de la Convención, y los principios recogidos en el artículo 3 común de las Convenciones de Ginebra, en perjuicio de Artemio Pantoja Ordóñez, Hernán Javier Cuarán Muchavisoy, Julio Milcíades Cerón Gómez, Edebraiz Cerón Rojas y William Hamilton Cerón Rojas y N/N Moisés.

Con fundamento en las pruebas aportadas a la Corte y agotadas las correspondientes etapas procesales, se pudo concluir que el Estado coIombiano no cumplió con su deber de garantizar la debida protección judicial, que no permitió el acceso a un recurso idóneo para las víctimas y sus familiares, quienes se vieron en completo estado de indefensión frente a la acción de agentes y autoridades del Estado, que injustificadamente se dilataron los respectivos procesos, que en su momento no se practicaron y se recaudaron las pruebas pertinentes.
La Corte, por unanimidad, declaró que la responsabilidad del Estado por la muerte de los señores anteriormente descritos e, igualmente, el Estado es responsable por la muerte de N.N./Moisés. No existen pruebas suficientes que permitan afirmar que Hernán Lizcano Jacanamejoy fue ejecutado en combate o extrajudicialmente. Mediante sentencia del Tribunal Contencioso Administrativo de Nariño del 15 de abril de 1993 se declaró responsable al Estado Colombiano por la muerte de Artemio Pantoja Ordóñez y Hernán Javier Cuarán Muchavisoy y, por ende, lo condenó al pago de daños y perjuicios morales y materiales causados a sus familiares. En cuanto al proceso penal militar, después de siete años aún se encontraba en la etapa de investigación y todavía no se había acusado formalmente a alguno de los responsables de los hechos (Corte Interamericana de Derechos Humanos, Informe 99).

\section{LA MASACRE DE MAPIRIPÁN}

El 12 de julio de 1997 aproximadamente un centenar de miembros de las Autodefensas Unidas de Colombia, grupo paramilitar, aterrizaron en el aeropuerto de San José de Guaviare (departamento del Guaviare), en vuelos irregulares procedentes de Neclocí y Apartadó (departamento de Antioquia). Es necesario tener en cuenta que el Ejército colombiano permitió dicho aterrizaje sin practicar ningún tipo de registro o anotación en los libros y fueron recogidos y transportados en dos camiones por miembros del Ejército, sin que éstos últimos practicaran ningún tipo de control; en un punto de la carretera se les unieron otros paramilitares y desde allí, por vía fluvial, pasando por un sitio en el que se encontraban una Brigada Móvil del Ejercito y la Infantería de Marina, sin ser detenidos, continuaron su recorrido sin inconvenientes por el río Guaviare, hasta quedar frente a Mapiripán (departamento del Meta).

Al amanecer del 15 de julio, más de cien hombres de las AUC armados y algunas personas que 
vestían prendas de uso privativo de las Fuerzas Militares rodearon Mapiripán por vía terrestre y fluvial, utilizando además radios de alta frecuencia. Tomaron control del pueblo, de las comunicaciones y de las oficinas públicas y procedieron a intimidar a sus habitantes, a secuestrar y producir la muerte de otros. Un Juez de Mapiripán, alarmado por la incursión, se comunicó con la Procuraduría Delegada para Derechos Humanos y con el Tribunal Superior del Distrito Judicial del Meta, el cual se abstuvo de realizar actuaciones investigativas. Asimismo, un ciudadano reportó la situación y la presencia de un jefe de las AUC a un coronel del Ejército, comandante del Batallón Joaquín París de San José del Guaviare que se encontraba bajo la jurisdicción del municipio de Mapiripán.

Un brigadier general, comandante de la Brigada VII, y un coronel, Comandante de la Brigada Móvil II, exhibieron completa inactividad funcional y operativa a pesar de tener conocimiento sobre la masacre; además, se dispuso la movilización injustificada de las últimas tropas del Batallón Joaquín París desde San José de Guaviare hacia otras localidades, dejando desprotegidas a las poblaciones de dicho lugar y de Mapiripán. Las AUC permanecieron en Mapiripán desde el 15 hasta el 20 de julio de 1997, lapso durante el cual impidieron la libre circulación a los habitantes de dicho municipio; también torturaron, desmembraron, desvisceraron, descuartizaron y degollaron aproximadamente $\mathrm{a} 49$ personas presuntas auxiliares, colaboradoras o simpatizantes de las Fuerzas Armadas Revolucionarias de Colombia (FARC) y arrojaron sus restos al río Guaviare. Además, una vez concluida la operación, destruyeron gran parte de la evidencia física, con el objeto de obstruir la recolección de la prueba.

La masacre ocurrida en Mapiripán, aunada al miedo que se repitieran hechos similares, al amedrentamiento por parte de paramilitares, a las vivencias de los días en que ocurrió la masacre,
Ios daños sufridos por las familias y la posibilidad de sufrir otros daños, en razón de tener que dar su testimonio o de haberlo dado, provocó el desplazamiento interno de familias enteras de Mapiripán. Algunas de las personas desplazadas no vivían propiamente en Mapiripán al momento de los hechos, pero se vieron igualmente obligadas a desplazarse como consecuencia de estos hechos. La fuerza pública llegó a Mapiripán el 22 de julio de 1997. La Fiscalía, junto con miembros de la Fuerza Pública y un delegado de la Presidencia de la República lograron ingresar a Mapiripán el 23 de julio de 1997. Los paramilitares impidieron que las autoridades judiciales realizaran sus funciones de investigación y de juzgamiento. Colombia, en relación con los hechos del presente caso, abrió procesos penales en la jurisdicción penal militar y ordinaria, procesos contenciosos administrativos y procedimientos disciplinarios.

En el presente caso, el conjunto de las faltas a los deberes de protección y de investigación ya establecidas, han coadyuvado a la impunidad de la mayoría de los responsables de las violaciones cometidas. Dichas faltas evidencian una forma de continuidad del mismo modus operandi de los paramilitares de encubrimiento de los hechos y han desembocado en la posterior falta de efectividad del proceso penal en curso por los hechos de la masacre, en la que participaron directamente al menos cien paramilitares con colaboración, aquiescencia y tolerancia de miembros de las Fuerzas Armadas colombianas.

Según fue establecido, antes de ser ejecutadas, las víctimas fueron privadas de libertad y fueron objeto de tortura o graves tratos crueles, inhumanos o degradantes. Los signos de tortura y las condiciones en que algunos familiares y testigos encontraron los cadáveres revelan no sólo la atrocidad y barbarie de los hechos, sino también que, en la menos cruel de las situaciones, las víctimas fueron sometidas a graves torturas psicológicas 
al presenciar las ejecuciones de otras personas y al prever su fatal destino, al verse sometidas a las condiciones de terror ocurridas en Mapiripán entre el 15 y el 20 de julio de 1997.

Por su parte, los familiares de las víctimas han sufrido daños como consecuencia de la desaparición y ejecución de sus seres queridos, por la falta de apoyo de las autoridades estatales en la búsqueda de los desaparecidos y el miedo a iniciar o continuar con las búsqueda de sus familiares ante posibles amenazas. Puesto que la mayoría de víctimas se encuentra desaparecida, los familiares no han contado con la posibilidad de honrar apropiadamente a sus seres queridos fallecidos.

La ausencia de una investigación completa y efectiva sobre los hechos y la impunidad parcial constituyen una fuente de sufrimiento y angustia adicionales para las víctimas y sus familiares. Todo lo anterior, además de haber afectado su integridad física y psicológica, ha impactado sus relaciones sociales y laborales, ha alterado la dinámica de sus familias $y$, en algunos casos, ha puesto en riesgo la vida e integridad personal de algunos de sus miembros.

\section{LA MASACRE DE ITUANGO}

En 1994, 1995, 1996, 1997, cuando el actual presidente del país Álvaro Uribe era el gobernador de Antioquia e impulsaba las Convivir, legitimando desde el gobierno el accionar paramilitar, por lo tanto, ocurrieron varias masacres en el país. Caseríos, municipios, veredas, corregimientos fueron perpetrados por los paramilitares, que recorrieron todos estos sitios torturando, asesinando, robando, saqueando, incendiando, destruyendo todo lo que estuviera a su paso. La masacre de Ituango estaba cantada, como lo estuvo la de Mapiripan, San Jose de Apartado, Pichili, las del Atrato, entre otras; la respuesta del gobierno que justificó esta la barbarie fue "me han dicho que son auxiliadores de la guerrilla". La innegable cooperación del Ejército en cada salvajada es evidente, desde los soldados rasos, quienes cambian su brazalete según el día, hasta sus altos mandos, quienes son enviados como diplomáticos a otros países o disputan curul en el actual gobierno.

Las Autodefensas Campesinas de Córdoba y Urabá (ACCU) se tomaron el norte de Antioquia e iniciaron una sistemática masacre (1997) por los corregimientos de la región como Puerto Valdivia, El Aro y así, hasta asesinar en 1998 al abogado y defensor de Derechos Humanos, que de tiempo atrás denunciaba esta situación, generando una crisis humanitaria que obligó el desplazamiento de los pobladores.

Duele tener que admitirlo, pero las condenas recientes de la Corte Interamericana de Derechos Humanos contra Colombia, por las masacres de Ituango y Mapiripán, ocurridas en los años 1996 y 1997, son absolutamente justas. Estas masacres, como todas las cometidas por los paramilitares, fueron crímenes atroces, de inaudita crueldad.

\section{LAS MASACRES DE LA GRANJA Y EL ARO (ANTIOQUIA)}

Diez años después de ocurridas las masacres de La Granja y El Aro, en las que murieron diecinueve personas a manos de las AUC, dicha Corte decidió que el Estado colombiano debe responder por esos hechos. La masacre de La Granja ocurrió el 11 de junio de 1997, cuando veintidós paramilitares irrumpieron en el corregimiento, ordenaron el cierre de establecimientos públicos y asesinaron de manera selectiva a cuatro campesinos.

La Corte dijo que las pruebas demostraron que los "paras" pasaron por la zona de Chapineros, luego de que un retén del Ejército fue levantado. El otro hecho ocurrió el 25 de octubre de 1997: los paramilitares atacaron el corregimiento El Aro, también 
en Ituango, reunieron a los habitantes en el parque central y asesinaron a quince habitantes. En los diferentes apartados de la providencia en mención se expresó por diferentes testigos, hechos desgarradores, los cuales demuestran que:

[...] Los responsables de los hechos en El Aro "se habían identificado como autodefensas". Cuando llegaron al pueblo, los paramilitares llevaron a varios pobladores a la plaza, los arrojaron al suelo y los colocaron en fila. Los paramilitares acusaron a todos de ser colaboradores de la guerrilla. Extendieron a las personas boca abajo, los pisotearon, y luego les dispararon [...] Cuando Ilegó un helicóptero, Ios paramilitares dijeron que el pasajero era Carlos Castaño. El pasajero del helicóptero se dirigió a la Inspección de Policía y habló con los que ahí se encontraban, incluyendo a uno que le decían "y un soldado conocido como 'Rambo'. A 'Junior' también le llamaron de Mauricio".

Entre los aproximadamente doscientos (200) hombres que incursionaron en El Aro, algunos eran conocidos como "Cobra", "Pescado" y "El Tigre". Los paramilitares se relacionaban con miembros del Ejército en Puerto Valdivia, incluso con "Rambo", quien era moreno y muy alto. "Rambo" había subido con soldados a El Aro, ocho días antes de la masacre y fue visto posteriormente en Puerto Valdivia. Luego de matar a varios residentes del pueblo, los paramilitares quemaron las casas, los locales y los ranchos a su alrededor entre los días jueves y viernes. El sábado los paramilitares salieron del pueblo luego de haberlo incendiado. El Aro "quedó acabado".

Los civiles enterraron a los muertos [...] El Gobernador de Antioquia envió un telegrama al Inspector de Puerto Valdivia solicitándole a éste que se comunicara con el Secretario de Gobierno, quien, a su vez, le solicitó que se comunicara con el comandante del Ejército del área y solicitara ayuda para recoger los ganados. Posteriormente el oficial llamó al teniente Bolaños, quien le respondió que eran "unos guerrilleros, que ese ganado era de la guerrilla, que eso ya se lo habían llevado" (Corte Interamericana de Derecho Humanos, julio de 2006).

En este proceso se presentaron distintas pruebas tales como documentales, testimoniales y periciales, de las cuales se concluyó que:

a) las autoridades no adoptaron las medidas preventivas a pesar de saber que existía una incursión paramilitar en Ituango; b) las masacres en Ituango fueron realizadas por grupos paramilitares que actuaron conjuntamente con las fuerzas armadas de Colombia, o que al menos contaron con la aquiescencia o tolerancia de éstas; y c) a un número grande de personas se les obligó a desplazarse sin asistencia de emergencia, ni apoyo estatal para su nuevo establecimiento y reintegración voluntaria.

Los actos supuestamente perpetrados por grupos paramilitares, tales como mutilaciones y otras torturas seguidas por ejecuciones extrajudiciales, habían sido realizados con "extrema brutalidad".

El grupo paramilitar involucrado permaneció varios días en la zona y recibió apoyo militar y logístico de las Fuerzas Armadas colombianas. En relación con los desplazamientos forzados, el Estado coIombiano estaba obligado, de conformidad con la legislación local, así como con la normativa internacional, a lo siguiente:

- Prevenir la masacre y desplazamiento.

- Investigar los actos violentos, llevar a cabo juicios y sancionar a los responsables.

- Proteger a la población desplazada de violaciones adicionales.

- Proveer a los desplazados con asistencia humanitaria en las áreas de alimentación, vivienda, salud, educación y vestimenta. 
- Asegurar el retorno seguro y voluntario a sus hogares, así como la reintegración local o el nuevo establecimiento en otra parte del país.

Se demostró que diecisiete campesinos de El Aro fueron privados de su libertad durante diecisiete días, al ser retenidos por el grupo paramilitar que controlaba el corregimiento durante los días de la incursión. Dicha incursión ocurrió con la aquiescencia o tolerancia de agentes del Ejército colombiano. A las personas retenidas se les privó su derecho a la libertad, con el propósito de obligarlas a recoger y arrear ganado sustraído de toda la región. Asimismo, se ha comprobado que agentes del Estado recibieron ganado usurpado de manos de los arrieros. Las autoridades departamentales no ayudaron a las presuntas víctimas en la recuperación de su ganado y no fueron a la finca en la cual éste supuestamente se encontraba.

Un menor de catorce años fue arbitrariamente privado de su derecho a la vida por el grupo paramilitar, mientras se encontraba trabajando en labores propias de la agricultura, el Estado colombiano no sólo no garantizó las especiales medidas de protección a las que tenía derecho en su calidad de niño, sino también que incumplió el deber de respetarlas. Antes de abandonar el corregimiento de El Aro, "los paramilitares destruyeron e incendiaron casi la totalidad de las casas del casco urbano a fin de causar terror y desplazamiento forzado".

Las decisiones del fallo de la Corte fueron:

- El Estado debe realizar las acciones necesarias para garantizar las condiciones de seguridad, para que los exhabitantes de los corregimientos de El Aro y La Granja, que se hayan visto desplazados, puedan regresar sus tierras.

- En un acto público, el Estado debe reconocer su responsabilidad internacional por las dos masacres, esto con presencia de altas autoridades.
- El Estado debe poner en marcha un plan de vivienda, mediante el cual se dote de viviendas adecuadas a aquellas víctimas sobrevivientes que perdieron sus casas y que así lo requieran.

- Fijar una placa en un lugar público apropiado en La Granja y El Aro, con el objeto de que las nuevas generaciones se enteren de los hechos que dieron lugar al fallo de la Corte Interamericana de Derechos Humanos.

- Implementar, en un plazo razonable, según la Corte, programas de educación en Derechos Humanos y Derecho Internacional Humanitario permanentes en las Fuerza Pública colombiana.

- Publicar, en el plazo de seis meses, en el Diario Oficial y en otro diario de circulación nacional, por una sola vez, el capítulo relativo a los hechos probados y la parte resolutiva del fallo sobre El Aro y La Granja.

\section{EL CASO GUTIÉRREZ SOLER}

El 24 de agosto de 1994, en horas de la tarde, el coronel de la Policía Nacional, Luis Gonzaga Enciso Barón, comandante de una unidad urbana de la Unidad Nacional Antiextorsión y Secuestro de la Policía Nacional (UNASE), y su primo, el teniente coronel (r) del Ejército, Ricardo Dalel Barón, se apersonaron en la carrera 13 con calle 63 de Bogotá, donde habían citado al señor Wilson Gutiérrez Soler. Los señores Enciso Barón y Dalel Barón lo detuvieron y lo condujeron al sótano de las instalaciones de la UNASE. Una vez en el sótano, el señor Gutiérrez Soler fue esposado a las llaves de un tanque de agua y sometido a torturas y tratos crueles, inhumanos y degradantes, consistentes en quemaduras en los órganos genitales y otras lesiones graves. Tres horas después de haber sido torturado, el señor Gutiérrez Soler fue entrevistado por funcionarios de la Oficina Permanente de Derechos Humanos, quienes le dijeron que para salvar su vida, respondiera a todo que sí. Por lo tanto, el señor Gutiérrez Soler fue inducido bajo 
coacción a rendir declaración "en versión libre" sobre los hechos motivo de la detención.

El señor Gutiérrez Soler no contó con la presencia de su representante legal ni con la de un defensor público, al rendir declaración. Para suplir la ausencia de un defensor, miembros de la fuerza pública solicitaron la asistencia de una religiosa, a fin de que compareciera en la referida diligencia junto con el señor Gutiérrez Soler. El Estado no efectuó esfuerzo alguno por contactar a un abogado que pudiera actuar como defensor técnico, aunque la sede de la UNASE se encuentra en una zona céntrica de la capital de Colombia.

Por unanimidad, la Corte declaró que el Estado violó el derecho a la Integridad Personal de la Convención Americana sobre Derechos Humanos en perjuicio del señor Wilson Gutiérrez Soler y su núcleo familiar. Asimismo, decidió que el Estado violó el derecho a la libertad personal, a las garantías judiciales, la protección judicial y no hizo lo suficiente para prevenir y sancionar los actos de tortura. La Corte dispuso que el Estado investigara los hechos denunciados, así como que identificara, juzgara y sancionara a los responsables.

Le ordenó implementar en los cursos de formación de los servidores públicos de la jurisdicción penal militar y de la fuerza pública un programa dirigido al análisis de la jurisprudencia del Sistema Interamericano de Protección de los Derechos Humanos y adoptar las medidas que sean necesarias para fortalecer los mecanismos de control existentes en los centros estatales de detención (Corte Interamericana de Derechos Humanos, 12 de septiembre de 2005, pp. 24-27 y 51-53).

Este caso es un vivo ejemplo de lo padecido por la familia Gutierrez Soler, a raíz de todas las violaciones a los derechos fundamentales materializadas por miembros de las Fuerzas Armadas, pues como se demostró varias fueron las instancias judiciales internas a las que recurrió Gutiérrez Soler en busca del restablecimiento de sus derechos, ante las cuales vio frustradas sus pretensiones, pero fue tan sólo once años después a los hechos padecidos y ante una Corte Internacional, que en cierta medida se vieron resarcidos sus sufrimientos, puesto que para este alto tribunal sí existió la prueba que demostró la veracidad de lo acontecido, el día de la retención ilegal de la que fue víctima, la cual estuvo acompañada de innumerables lesiones causadas por los actos de tortura padecidos.

\section{CONCLUSIÓN}

Con la implementación de la Corte Interamericana de Derechos Humanos se habla de la posibilidad que toda persona tiene para acceder a la justicia en esta instancia, es decir, que se pueden acudir a los medios jurídicos nacionales e internacionales ${ }^{9}$, en busca de la protección de los derechos que poseen las víctimas y de la vigencia de los derechos fundamentales de todo pueblo, dando prevalencia a las libertades y garantías plasmadas en las normas de Derecho Internacional.

Sobre el conflicto interno colombiano, se debe tener como punto de partida, que el ser humano posee su propia naturaleza (Fromm, s.f.), teniendo

$9 \quad$ Acceso a la justicia artículos 8.1 del Pacto de San José de Costa Rica: Toda persona tienen derecho a ser oída, con las debidas garantías y dentro de un plazo razonable, por un juez o autoridad competente, independiente e imparcial, establecida con autoridad por la ley, en la sustanciación de cualquier acusación penal formulada contra ella, o para la determinación de sus derechos y obligaciones de orden civil, laboral, fiscal o de cualquier otro carácter.

Artículo 25 de la Convención Americana: 1. Toda persona tiene derecho a un recurso sencillo y rápido o a cualquier otro recurso efectivo ante los jueces o tribunales competentes, que la ampare contra actos que violen sus derechos fundamentales reconocidos por la constitución, la ley o la presente Convención, aun cuando tal violación sea cometida por personas que actúen en ejercicio de sus funciones oficiales. 2. Los Estados partes se comprometen: a) a organizar que la autoridad competente prevista por el sistema legal del Estado decidirá sobre los derechos de toda persona que interponga tal recurso; b) a desarrollar las posibilidades de recurso judicial. C) a garantizar el cumplimiento, por las autoridades competentes de toda decisión en que se haya estimado procedente el recurso. 
presente que puede variar el contenido, ya que su esencia brota de las condiciones biológicas, físicas, mentales, sociales, ambientales, espirituales, las cuales permiten la existencia y evolución en sociedad de los pueblos, de ahí, que el conflicto armado que se vive en nuestro país, a través de la historia haya tenido varias manifestaciones de violencia y actividad criminal, como ha sido el origen y evolución de los grupos armados al margen de la ley (FARC-EP, ELN y Autodefensas), grupos criminales, de los que se desprende la tendencia y los indicadores de violencia y actividad criminal.

Lo anterior trae como consecuencia que el Estado deba adoptar medidas inmediatas y concretas para combatir el elevado grado de impunidad ${ }^{10}$ que existe frente a las atrocidades cometidas por los grupos al margen de la ley, de ahí, que el Estado tenga la obligación de combatir estos actos, por los medios legales disponibles, para que no se propicie la repetición crónica de actos inhumanos.

Con respecto a este factor, se debe señalar que son bastantes los casos de repetición de dicha actividad criminal, como lo fue con los casos de la Rochela, los diecinueve comerciantes, la masacre de Mapiripan, la masacre de Ituango, la de Álvarez, las Palmeras, la de pueblo Bello, entre otras, actos delictivos que sin lugar a dudas fueron cometidos en el contexto del conflicto armado que vive nuestro país, teniendo como consecuencias un gran número de víctimas, que fueron desplazados o ejecutados, pero a través de la jurisprudencia de la Corte Interamericana de Derechos Humanos, en cierta medida, se han podido resarcir los derechos

10 La Corte interamericana definió la impunidad como la falta en su conjunto de investigación, persecución, captura, enjuiciamiento y condena de los responsables de las violaciones de los derechos protegidos por la Convención Americana, toda vez que el Estado tiene la obligación de combatir tal situación por todos los medios legales disponibles, ya que la impunidad propicia la repetición crónica de las violaciones de Derechos Humanos y la total indefensión de las víctimas y de sus familiares (Corte IDH, caso Ivcher Bronsein, sentencia 6 de febrero de 2001). de las víctimas, es decir, que mediante estos fallos se puede hablar de un acercamiento a la verdad, justicia y reparación.

Por esto, las sentencias emitidas por la Corte se han caracterizado por la constante evolución de su jurisprudencia, lo cual engrandece la protección de los Derechos Humanos, de lo que se desprende la razón de ser del procedimiento preestablecido ante los órganos del sistema interamericano, en cada una de sus fases, razón por la cual es preciso estudiar casos concretos que nos permitan observar las posiciones de las partes que integran la litis; aunado a lo anterior, la decisión emitida por la Corte, la interrelación e independencia de la rama del Derecho Internacional, bien sea de carácter universal o regional. Lo anterior se busca la responsabilidad estatal, pues el Estado debe responder por los actos y omisiones ante el derecho internacional, de ahí que se deba verificar si cumple con los deberes adquiridos ante la comunidad internacional, de respeto por los Derechos Humanos en un territorio, por lo que se debe tener presente el principio de derecho internacional del pacta sunt servanda" .

Cuando se entra en el escenario de las violaciones de los Derechos Humanos, surge el cuestionamiento de por qué se responsabiliza al Estado y no a los grupos ilegales. Los Estado son juzgados, porque su compromiso ineludible es respetar los derechos consagrados en los tratados internacionales. Pero no menos cierto es que los grupos ilegales no responden por las violaciones de los Derechos Humanos, lo hacen en el ámbito interno ante la justicia penal y en el ámbito externo terminarán haciéndolo ante la Corte Penal Internacional si la justicia interna falla. No obstante, desde el punto de vista ético resulta más reprobable que quien representa la institucionalidad termine involucrado

11 Locución latina, la cual demanda que los pactos o tratados se deben mantener, al igual que lo estipulado por las partes, cualquiera que sea la forma de estipulación, debe ser fielmente cumplido, es decir, que se ha de estar a lo pactado. 
en crímenes, sea incapaz de juzgar las propias violaciones de sus administrados.

En el último tiempo, la CIDH ha proferido importantes sentencias condenatorias contra el Estado colombiano, que han marcado precedentes sobre la responsabilidad de las autoridades en graves violaciones de Derechos Humanos. En efecto, en sentencias como 19 Comerciantes, Mapiripán, Ituango y la Rochela, la Corte ha establecido responsabilidad del Estado en hechos que fueron cometidos por grupos paramilitares con la participación, anuencia o inactividad de miembros de la Fuerza Pública. Estos fallos también implican un reproche a la justicia ordinaria y a la justicia penal militar por su ineficacia para establecer las responsabilidades correspondientes y restituir los derechos de las víctimas.

Los fallos de la Corte deberían servir para una reflexión que está en mora de hacerse, y es la vinculación de miembros del Estado en la conformación y accionar de grupos paramilitares, tema que ha sido eludido de manera sistemática en el proceso de desmovilización que se tramita en el contexto de la aplicación de la Ley de Justicia y Paz, y que, junto con el compromiso de sectores económicos, es el otro inconcluso que le hizo falta al debate sobre el origen y desarrollo del paramilitarismo en Colombia.

Este debate hay que hacerlo ya, para que no pase como en el caso del Palacio de Justicia, cuando se amnistió a quienes hacían parte del grupo que originó la toma, y hoy en día se está juzgando a quienes realizaron la retoma, generando una situación de inequidad en el tratamiento que para muchos sectores de opinión es inaceptable.

\section{BIBLIOGRAFÍA}

Becerra, Andrea. (Septiembre de 2006) Seminario realizado en la Universidad Santo Tomás, Seminario sobre la Ley de Justicia y Paz. Miembro de ILSA. Actual miembro del Observatorio a la verdad, la justicia y la reparación en Colombia. Bogotá.

Convención Interamericana de Derechos Humanos. (7 al 22 de noviembre de 1969) Pacto de San José de Costa Rica, Tratados Multilaterales. Recuperado en: www.oas.org [22 de agosto de 2007].

Corte Interamericana De Derechos Humanos. Información de la Página Web de la CIDH. Recuperado en: www.corteidh.org.cr [23 de agosto de 2007].

Chopra Deepak (2005) La paz es el camino: el final de la guerra y la violencia. Bogotá D.C.: Grupo Norma Editores.

Escuela Judicial Rodrigo Lara Bonilla. (2006) Derechos Humanos y Derecho Internacional Humanitario. Bogotá: Imprenta Universidad Nacional.

Ríos González Gerney. (2001) Guerra y paz, los rostros del conflicto ( 1 a edición). Bogotá: Fundación Centro Andino de Estudios. 